\title{
Brief Report: Matrix Model as an Intensive Rehabilitation in Three Methadone Services in Iran
}

\author{
Sara Sami', Mohammad Effatpanah², Afsaneh Moradi', Omid Massah ${ }^{3 *}$ \\ 1. Department of Educational Psychology, Faculty of Educational Sciences and Psychology, Alzahra University, Tehran, Iran \\ 2. School of Medicine, Ziaeian Hospital, International Campus, Tehran University of Medical Sciences, Tehran, Iran. \\ 3. Substance Abuse and Dependence Research Center, University of Social Welfare \& Rehabilitation Sciences, Tehran, Iran
}

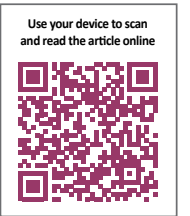

Citation: Sami S, Effatpanah M, Moradi A, Massah O. Matrix Model as an Intensive Rehabilitation in Three Methadone Services in Iran. Iranian Rehabilitation Journal. 2017; 15(3):293-297. https://doi.org/10.29252/NRIP.IRJ.15.3.293

https://doi.org/10.29252/NRIP.IRJ.15.3.293

Article info:

Received: 4 May 2017

Accepted:17 Jul. 2017
Keywords:

Dependence, Methamphetamine, Methadone, Matrix model, Treatment

\section{ABSTRACT}

Objectives: The Matrix Model is used for MA dependence in methadone services in Iran, the most populated Persian Gulf country. However, there are no studies of the efficacy of the Matrix Model for MA dependence while in treatment. The present study reports on the efficacy of sixteen weeks of the Matrix Model for MA abstinence and general health.

Methods: There were MA-dependent male $(n=30)$ and female $(n=30)$ patients in the study sites whom received the Matrix Model. The sites included three large methadone clinics in Tehran, Iran during 2015. The Persian versions of the Time Line Follow Back (TLFB) and the General Health Questionnaire-28 (GHQ-28) were completed by each participant at baseline and treatment weeks of four, ten and sixteen. Abstinence from MA was confirmed on the TLFB and with doing urinalyses at the same time.

Results: All subjects were daily MA users on the TLFB at baseline. General health was poor among all subjects at baseline. There was no reported subject attrition at baseline. But, ten subjects left the Matrix treatment before the end of week nine and 21 subjects left the Matrix treatment before the end of week 13 . At week 4 , only $20 \%$ of the subjects were abstinent from MA. At week ten, $35 \%$ of the subjects were abstinent from MA while at week $16,65 \%$ of the subjects were abstinent from MA. The Matrix Model led to an increased rate of abstinence from MA $(\mathrm{P}<0.001)$ at week 16 . Those who completed the treatment were more likely to report improved general health $(\mathrm{P}<0.05)$ than those who did not at week 16 .

Discussion: The study indicated that the Matrix Model significantly increased the rate of abstinence from MA. But, at week sixteen, subject attrition was high. This issue demands further research.

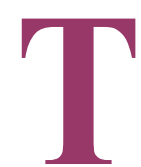

\section{Introduction}

here is growing concern about methamphetamine (MA) dependence in many countries and presentations to treatment services are reportedly increasing [1]. MA is the most widely used illicit drug in the world after cannabis [1]. Iran (also called Persia) has one of the highest rates of MA dependence

* Corresponding Author:

Omid Massah, MD

Address: Substance Abuse and Dependence Research Center, University of Social Welfare and Rehabilitation Sciences, Koodakyar Deadlock, Daneshjoo Blv., Evin, Tehran, Iran.

Tel: +98 (21) 22180097

E-mail: omchomch@gmail.com 
in the world which has led to psychological problems and poor health among this group [2]. MA dependence in methadone treatment has been also led to injection [3].

Psychological treatments are the only interventions for MA dependence [4]. The Matrix Model is the most suggested treatment that provides a framework for engaging MA-dependent people in treatment and helping them achieve abstinence from MA [5]. The Matrix Model is provided three-times a week, 16 week intensive outpatient program. The Matrix Model makes use of a number of different therapeutic modalities, such as cognitive behavioural therapy, motivational enhancement therapy, group therapy, family and couples therapy, individual therapy, and 12 step facilitation. Participants in the treatment have their urine tested for MA use on a regular basis. Participants learn about issues critical to MA dependence and relapse, receive direction and support from a trained psychologist, and become familiar with self-help treatments [6]. Participants are also monitored for MA use through urine testing [4].

The psychologist works simultaneously as teacher, enhancing a positive, encouraging relationship with the participant and using that relationship to increase positive behavior change. The relationships between the psychologists and the participants is authentic and direct but not confrontational. Psychologists are trained to conduct treatment sessions in a way that increases the participants' self-esteem, and self-worth [4-6]. The Matrix Model has been provided for MA dependence in methadone treatment in Iran. But, there are few studies of the efficacy of the Matrix Model for MA dependence in methadone treatment services. The study aimed to address this critical gap in the literature.

\section{Methods}

\section{Design and centres}

This study is a report on the trend of the Matrix Model conducted for methadone patients with MA dependence. The sites included three large methadone clinics in Tehran, Iran. The centres were located in middle class areas of Tehran.

\section{Subjects}

There were MA-dependent male $(n=30)$ and female $(n=30)$ patients in the study. All of them were daily MA users in methadone treatment. MA dependence in treatment was defined as meeting the Diagnostic and Statistical Manual of Mental Disorders, fourth edition
(DSM.IV-TR) criteria for MA dependence [7]. Other inclusion criteria included age of at least 18 years, male or female gender and being in methadone treatment for at least four months. Exclusion criteria included reporting drug intoxication or withdrawal symptoms at the time of interviewing which were likely to negatively impact on interview procedures or completing the study assessments.

\section{Questionnaires}

The Persian versions of the Time Line Follow Back (TLFB) and the General Health Questionnaire-28 (GHQ-28) were completed by each participant at baseline and treatment weeks of four, ten and sixteen. Abstinence from MA was confirmed on the TLFB and doing urinalyses at the same time. The TLFB is a calendar-like questionnaire [8]. It takes at most ten minutes to complete the TLFB. There is no cut-off point [8]. More number of days of MA use on the questionnaire show more problems [8]. The TLFB was assessed for reliability in a two week-pre-test-post-test on 15 male and female methadone patients. The reliability of the questionnaire was high $(\mathrm{a}=0.89)$.

The General Health Questionnaire (GHQ-28) is a highly approved scale which measures general health [9]. The GHQ-28 evaluates somatic problems, anxiety, social dysfunction and major depression [9]. Scores on the GHQ-28 are between 0 and 28. Higher scores on the GHQ-28 indicate more psychiatric problems [9]. The GHQ-28 was assessed for reliability in a two week-pretest-post-test on 15 male and female methadone patients with MA dependence. The reliability of the questionnaire was high $(\mathrm{a}=0.91)$.

\section{Ethical approvals}

All subjects were informed that lack of participation in the study would not impact on their methadone treatment or their relationships with the staff. Each subject was informed that participation was voluntary and confidential. Subjects received US\$ 10 for study participation at each assessment point. Consent form was obtained from each subject.

\section{Data analyses}

Chi square tests were used for categorical variables and independent samples t-tests were used for continuous variables. Repeated measures ANOVA were used to assess the outcomes at baseline and weeks four, ten and sixteens. Data were analyzed using SPSS version 23. 


\section{Study procedures}

The Matrix Model was implemented during sixteen weeks by three well-trained clinical psychologists. The whole study procedure took at the study sites during 2015. Three well-trained clinical psychologists interviewed with the participants and completed the questionnaires at baseline and weeks four, ten and sixteens. Urinalyses were conducted by three registered nurses in the study sites over the same time. Subjects were not informed about the date of doing urinalyses.

\section{Results}

The two groups were not different in terms of the mean age (36.2 yrs. vs. 35.7 yrs., $\mathrm{t}=0.76, \mathrm{P}=0.9$ ), mean education ( 8.2 yrs. vs. 7.9 yrs. $\mathrm{t}=0.86, \mathrm{P}=0.8$ ), stable living condi- tions $\left(76.6 \%\right.$ vs. $\left.73.3 \%, \mathrm{X}^{2}=0.67, \mathrm{P}=0.7\right)$, married status $\left(60.0 \%\right.$ vs. $\left.63.3 \%, \mathrm{X}^{2}=0.91, \mathrm{P}=0.6\right)$, lifetime MA treatment ( $33.3 \%$ vs. $\left.36.6 \%, \mathrm{X}^{2}=0.37, \mathrm{P}=0.09\right)$ and lifetime imprisonment ( $23.3 \%$ vs. $20.0 \%, \mathrm{X}^{2}=0.42, \mathrm{P}=0.11$ ) (Table 1 ).

All subjects were daily users of MA on the TLFB at baseline. Overall, ten subjects left the Matrix treatment before the end of week nine and 21 subjects left the Matrix treatment before the end of week 13. At week 4, only $20 \%$ of the subjects were abstinent from MA. At week ten, $35 \%$ of the subjects were abstinent from MA while at week $16,65 \%$ of the subjects were abstinent from MA. The Matrix Model led to an increased rate of abstinence from MA $(\mathrm{F}=125, \mathrm{P}<0.001)$ at week 16 (Table 2). Urinalyses confirmed the self-reported abstinence from MA over the same time. There was no in-

Table 1. Baseline characteristics of the subjects

\begin{tabular}{|c|c|c|c|c|c|}
\hline Characteristics & Men $(n=30)$ & Women $(n=30)$ & Total $(\mathrm{N}=60)$ & $x^{2} / t$ & $\mathbf{P}$ \\
\hline Mean age (years) & $36.2(\mathrm{SD}=5.6)$ & $35.7(S D=6.8)$ & $35.2(\mathrm{SD}=6.3)$ & $t=0.76$ & 0.9 \\
\hline Mean education (years) & $8.2(\mathrm{SD}=9.3)$ & $7.9(\mathrm{SD}=8.6)$ & $7.8(\mathrm{SD}=7.4)$ & $\mathrm{t}=0.86$ & 0.8 \\
\hline Stable living conditions & $23(76.6 \%)$ & $22(73.3 \%)$ & $45(75.0 \%)$ & $X^{2}=0.67$ & 0.7 \\
\hline Married status & $18(60.0 \%)$ & $19(63.3 \%)$ & $37(61.6 \%)$ & $X^{2}=0.91$ & 0.6 \\
\hline Lifetime MA treatment & $10(33.3 \%)$ & $11(36.6 \%)$ & $21(35.0 \%)$ & $X^{2}=0.37$ & 0.9 \\
\hline Lifetime imprisonment & $7(23.3 \%)$ & $6(20.0 \%)$ & $13(21.6 \%)$ & $X^{2}=0.42$ & 0.11 \\
\hline
\end{tabular}

Table 2. TLFB scores over time

\begin{tabular}{lccccc}
\hline Characteristics & Rate of Abstinence (\%) & Treatment Completers & None-Treatment Completers & F & P \\
\hline Baseline $(n=60)$ & 0 & 0 & 0 & - & - \\
\hline Week $4(n=60)$ & 20 & 12 & 48 & 36 & 0.62 \\
\hline Week $10(n=50)$ & 35 & 17 & 33 & 37 & 0.66 \\
\hline Week 16 $(n=39)$ & 65 & 25 & 14 & 125 & $0.001^{*}$ \\
\hline
\end{tabular}

Iranlan Rehabilluton Journal

Table 3. GHQ-28 scores over time

\begin{tabular}{|cccccc}
\hline Characteristics & Rate of Abstinence (\%) & Treatment Completers & None-Treatment Completers & F & P \\
\hline Baseline $(n=60)$ & 0 & 0 & 0 & - \\
\hline Week $4(n=60)$ & 20 & 12 & 48 & 42 & 0.64 \\
\hline Week 10 $(n=50)$ & 35 & 17 & 33 & 38 & 0.68 \\
\hline Week 16 $(n=39)$ & 65 & 25 & 14 & 126 & $0.05 *$ \\
\hline
\end{tabular}

Mranlan Rekhabillution Dourna 
consistency between self-reports of abstinence from MA and urinalyses.

The GHQ-28 scores have been reported in Table 3. There was no considerable change in the GHQ-28 scores during the study. However, those who completed the treatment were more likely to report improved general health $(\mathrm{F}=126, \mathrm{P}<0.05)$ than those who did not at week 16 (Table 3).

\section{Discussion}

The study indicated that completing sixteen weeks of the Matrix Model was significantly associated with abstinence from MA and improved psychological wellbeing. This study is important. To date, this is the first report of Iran for MA dependence among male and female methadone patients.

These study findings are consistent with several studies. In a quasi-experimental study, people with MA dependence at drug treatment services were interviewed. Overall, 30 patients were selected and randomly assigned to an experimental group and a control group (i.e. 15 patients for each group). The experimental group was treated with the Matrix model. The control group remained on a waiting list. Both groups completed the self-efficacy questionnaire at baseline, post-treatment and 90 days later (follow-up) assessed by urinalyses. The study showed the efficacy of the Matrix treatment in preventing MA relapse and increasing self-efficacy among participants to manage MA [10].

Rawson and colleagues (2004) evaluated the effectiveness of the Matrix Model in comparison with a control condition for MA dependence. The Matrix Model significantly led to an increased number of urine specimens free from MA and high treatment retentions in the intervention group at post-treatment [11]. Further studies are needed to assess the effectiveness of the Matrix Model in increasing abstinence from MA and improving general health.

The Matrix Model can lead to significant effects at post-treatment and reduce MA dependence [12]. By using this intensive model, psychologists can gradually supervise the process of change during sixteen weeks of treatment $[13,14]$. However, it should be noted that the Matrix model is appropriate when intensive staff training is provided and the clients prefer a long-term intervention [14]. Furthermore, clients should be able to pay for the long-term procedure of their treatment [12-14]. These issues should be considered in conducting future studies.
The current brief report have several limitation. First the treatment was long. Second, there were no many defined outcome measures to evaluate. Furthermore, there were no data analyses in terms of the TLFB, the GHQ28 and the gender. Further studies are suggested.

\section{Conclusion}

The study indicated that the Matrix Model significantly increased the rate of abstinence from MA. But, at week sixteen, subject attrition was high. This issue demands further research.

\section{Acknowledgments}

This research did not receive any specific grant from funding agencies in the public, commercial, or not-forprofit sectors. The authors acknowledge all people who helped with conducting the research, especially patients and staff.

\section{Conflict of Interest}

The authors declared no conflicts of interest.

\section{References}

[1] United Nations Office on Drugs and Crime. World Drug Report 2004. Vienna: United Nations Publications; 2004.

[2] Shadloo B, Amin Esmaeili M, Haft-Baradaran M, Norooz A, Ghorban Jahromi R, Rahimi-Movaghar A. Use of amphetamine-type stimulants in the Islamic Republic of Iran, 20042015: A review. Eastern Mediterranean Health Journal. 2017 23(3):245-56. PMID: 28493273

[3] Alam Mehrjerdi Z, Abarashi Z, Noroozi A, Arshad L, Zarghami M. Correlates of shared methamphetamine injection among methamphetamine injecting treatment seekers: The first report from Iran. International Journal of STD \& AIDS 2013; 25(6):420-7. doi: 10.1177/0956462413512806

[4] Huber A, Ling W, Shoptaw S, Gulati V, Brethen P, Rawson R. Integrating treatments for methamphetamine abuse: A psychosocial perspective. Journal of Addictive Diseases. 1997; 16(4):41-50. doi: 10.1080/10550889709511142

[5] Rawson RA, Shoptaw SJ, Obert JL, McCann MJ, Hasson AL Marinelli Casey PJ, et al. An intensive outpatient approach for cocaine abuse treatment. Journal of Substance Abuse Treatment. 1995; 12(2):117-27. doi: 10.1016/0740-5472(94)00080-b

[6] Rawson RA, Huber A, McCann M, Shoptaw S, Farabee D, Reiber C, et al. A comparison of contingency management and cognitive behavioral approaches during methadone maintenance treatment for cocaine dependence. Archives of General Psychiatry. 2002; 59(9):817. doi: 10.1001/archpsyc.59.9.817 
[7] American Psychiatric Association. Diagnostic and statistical manual of mental disorders. Washington: American Psychiatric Association; 2000.

[8] Sobell LC, Sobell MB, Buchan G, Cleland PA, Fedoroff I, Leo GI. The reliability of the Time Line Follow Back method applied to drug, cigarette, and cannabis use. Paper presented at the $30^{\text {th }}$ Annual Meeting of the Association for Advancement of Behavior Therapy. 1996 November 3-5; New York, United States.

[9] Khosravi A, Mousavi SA, Chaman R, Kish MS, Ashrafi E, Khalili M, et al. Reliability and validity of the Persian version of the World Health Organization-five well-being index. International Journal of Health Studies. 2015; 1(1):17. doi: 10.22100/ijhs.v1i1.24

[10] Ghasemnezhad S, Ghasemian D, Gheytarani B, Ghorbani F, Ghahari S. The effectiveness of Matrix treatment to relapse prevention and increase self efficacy in people withdrawing methamphetamine. International Journal of Medical Research and Health Sciences. 2016; 5(8):340-5.

[11] Rawson RA, Marinelli-Casey P, Anglin MD, Dickow A, Frazier Y, Gallagher C, et al. A multi-site comparison of psychosocial approaches for the treatment of methamphetamine dependence. Addiction. 2004; 99(6):708-17. doi: 10.1111/j.1360-0443.2004.00707.x

[12] Buxton JA, Dove NA. The burden and management of crystal meth use. Canadian Medical Association Journal. 2008; 178(12):1537-9. doi: 10.1503/cmaj.071234

[13] Magidson JF, Gouse H, Burnhams W, Wu CYY, Myers B, Joska JA, et al. Beyond methamphetamine: Documenting the implementation of the Matrix model of substance use treatment for opioid users in a South African setting. Addictive Behaviors. 2017; 66:132-7. doi: 10.1016/j.addbeh.2016.11.014

[14] Hill R. Evidence-based practices for treatment of methamphetamine dependency: A review. Guelph: Community Engaged Scholarship Institute; 2015. 